ISSN 2236-0859

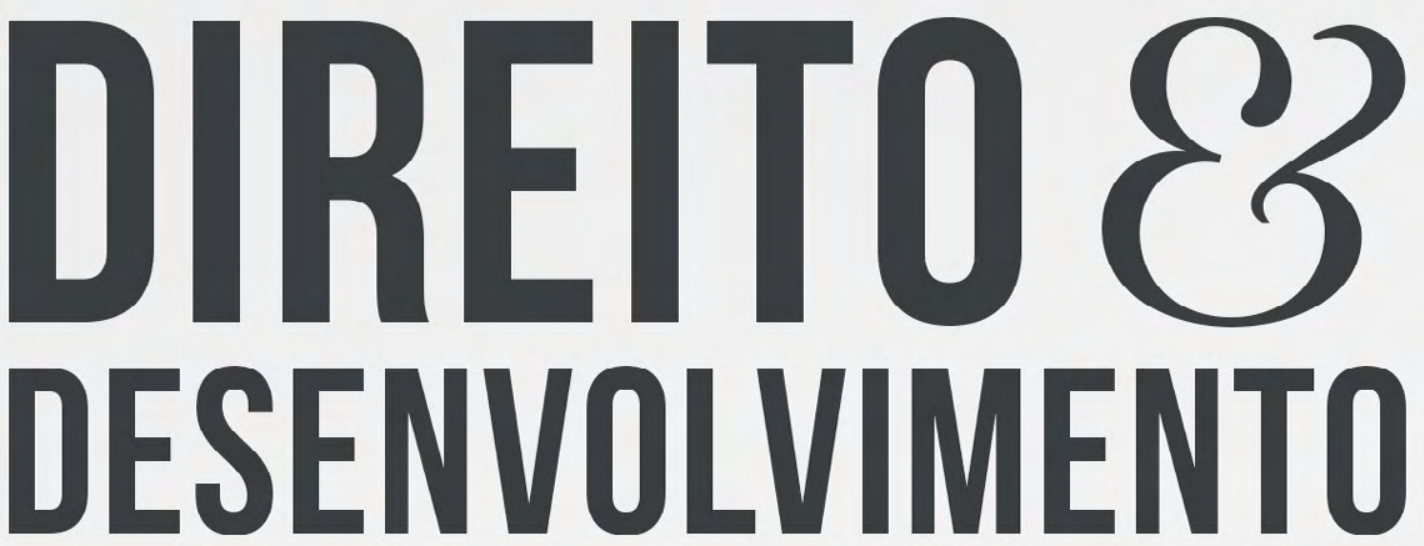

REVISTA DO PROGRAMA DE PÓS-GRADUAÇÃO EM DIREITO MESTRADO EM DIREITO E DESENVOLVIMENTO SUSTENTÁVEL

BIOTECNOLOGIA: NFLLUENCIA NA DIGNIDADE HUMANA

E A NECESSIDADE DE SUA REGULAMENTAÇÃO

LORENA NASCIMENTO RAMOS DE ALMEIDA

ÁLVARO RICARDO DE SOUZA CRUZ 


\title{
BIOTECNOLOGIA: INFLUÊNCIA NA DIGNIDADE HUMANA E A NECESSIDADE DE SUA REGULAMENTAÇÃO
}

\author{
BIOTECHNOLOGY: INFLUENCE ON HUMAN \\ DIGNITY AND THE NEED FOR ITS REGULATION
}

Recebido: 09/12/2017

Aprovado: 25/03/2018

Lorena Nascimento Ramos de Almeida* Álvaro Ricardo de Souza Cruz**

RESUMO: O presente trabalho visa estudar influência da biotecnologia - sobretudo pela técnica da eugenia - na dignidade humana, de forma que consigamos traçar uma perspectiva sobre a necessidade de regulamentação do exercício desta tecnologia e, se tal normatização deve seguir um viés restritivo ou liberal de sistematização. Após tal delimitação, buscaremos determinar alguns dos desafios que serão enfrentados pelo ente normatizador com a finalidade de evitar os percalços que a eugenia positiva possa trazer à dignidade humana. Para tal objetivo científico, procederemos um estudo qualitativo do tipo exploratório, com base no levantamento bibliográfico do tema controvertido, tomando como ponto de partida a discussão entre Ronald Dworkin e Jürgen Habermas.

Palavras-chave: Biotecnologia. Eugenia. Dignidade humana. Desafios da Regulamentação.

\begin{abstract}
The present work aims to study the influence of biotechnology - especially by the technique of eugenics - in human dignity, so that we can delineate a perspective on the need for regulation of the exercise of this technology and, if such normalization should follow a restrictive or liberal bias of systematization. After this delimitation, we will try to determine some of the challenges that will be faced by the normative entity in order to avoid the obstacles that positive eugenics can bring to human dignity. For this scientific objective, we will carry out a qualitative study of the exploratory type, based on the bibliographical survey of the controversial subject, taking as a starting point the discussion between Ronald Dworkin and Jürgen Habermas.
\end{abstract}

Keywords: Biotechnology. Eugenics. Human dignity. Regulatory Challenges.

\footnotetext{
* Mestranda em Direito Público pela Pontifícia Universidade Católica de Minas Gerais. Especialista em Direito Administrativo e Direito Constitucional pela Faculdade Internacional Signorelli. E-mail: lorenanra@gmail.com

** Pós-Doutor em História pela UFMG (2017). Doutor em Direito pela Universidade Federal de Minas Gerais (2003). ). Atualmente é Procurador da República do Ministério Público Federal e Professor Adjunto III da Pontifícia Universidade Católica de Minas Gerais. E-mail: alvaro.sc@terra.com.br
} 


\section{INTRODUÇÃO}

O desenvolvimento das ciências observou um crescimento exponencial nas últimas décadas. Alavancado pelas tecnologias de informação, pesquisadores de todo o mundo desenvolvem suas pesquisas em conjunto e, a troca de informações faz com que erros e acertos sejam compartilhados em tempo real, desenvolvendo toda comunidade científica como um todo.

A realidade da tecnologia atual deixaria a obra de ficção "1984" de George Orwell (1999), publicada em 1949 com ares de premonição, e, vislumbrando esse progresso acelerado e surpreendente, é necessário discutir-se os possíveis efeitos do desenvolvimento da tecnologia na sociedade, bem como, a necessidade de proteção dos direitos e garantias fundamentais - sobretudo da dignidade humana - através de regulamentação, quando estes se chocam com os caminhos traçados pelo avanço tecnológico.

No presente trabalho visamos analisar mais especificamente a biotecnologia sob o prisma da eugenia e os efeitos potenciais de seu desenvolvimento fronte aos Direitos Humanos sob o enfoque da dignidade humana. Nesse ínterim buscaremos explorar os diferentes prismas pelos quais se pode vislumbrar a biotecnologia, tomando por marco teórico o estudo de Habermas (2004), principalmente em sua obra: "O futuro da natureza humana: a caminho de uma eugenia liberal?".

Além disso, como visamos estudar a subsunção da biotecnologia aos Direitos Humanos, também faremos uma análise das concepções de dignidade humana tomadas por Brownsword (2004), que divide Direitos Humanos como autonomia e como restrição, sendo tal dimensão extremamente relevante para o posicionamento final que buscaremos com o presente trabalho: afinal, é necessária regulação da biotecnologia? E, se a resposta for positiva, quais os maiores desafios a serem enfrentados e superados para efetivamente regulamentar e evitar os percalços que a biotecnologia poderia trazer para a Dignidade humana?

\section{OS DESAFIOS DA BIOTECNOLOGIA SOB O PRISMA DA DIGNIDADE HUMANA}

O desenvolvimento científico, em muitas ocasiões se choca com diferentes perspectivas da dignidade humana. Para análise específica da biotecnologia eugênica far-se-á necessária a delimitação entre os diferentes prismas da eugenia e os diferentes prismas da dignidade humana e suas interconexões.

\subsection{Os Diferentes Prismas da Eugenia}

Tendo em vista a enorme amplitude do tema biotecnologia, uma vez que toda e qualquer aplicação de tecnologia à biologia - estudo da vida e dos organismos vivos - poderá ser apreendida como biotecnologia, buscaremos restringir nosso espectro de estudo.

Isso porque, a nosso ver, existem várias biotecnologias que já são utilizadas há vários anos, e, em que pese não serem comprovadamente seguras, não apresentam riscos iminentes à dignidade humana. Citemos como exemplo o congelamento do cordão umbilical do feto, para posterior uso das suas células como terapia do próprio indivíduo, ou mesmo o desenvolvimento dos produtos transgênicos - que, mesmo muito contestados, insurgiram-se como uma realidade mundial que dificilmente deixará de existir.

Assim sendo, focaremos nossa pesquisa na biotecnologia conhecida como eugenia: "o estudo dos agentes sob o controle social que podem melhorar ou empobrecer as qualidades raciais das futuras gerações seja física ou mentalmente." (GALTON, 1865, apud GOLDIM, 1998), ou seja, a utilização da tecnologia, para programação genética do ser humano, seja pré ou pós implantação uterina - com foco na manipulação préimplantação, momento em que acontecem, geralmente, as manipulações genéticas do feto.

Nesse sentido, não buscaremos desenvolver maiores discussões acerca das teorias concepcionistas ou natalistas, uma vez que, havendo a alteração genética, os dilemas aqui tratados subsistirão, 
independentemente do marco inicial que se adote para que o ser humano passe a ser detentor de personalidade e sujeito de direitos.

A teoria que adotaremos para diferenciar os prismas da eugenia foi formulada por Habermas (2004), tendo o filósofo da Escola de Frankfurt dividido a eugenia em positiva ou negativa e liberal ou conservadora.

Primeiramente passaremos a distinguir a eugenia positiva da eugenia negativa: a eugenia negativa teria caráter terapêutico, de tratamento de doenças em nível genético, ou seja, após um diagnóstico genético do embrião (pré ou pós implantação uterina), caso seja verificada a probabilidade ou certeza de que o mesmo seria portador de uma doença grave, haveria plausibilidade de utilização da tecnologia para curar ou diminuir as possibilidades do desenvolvimento de tal doença; portanto, estaríamos fronte a uma eugenia negativa, que retira a condição maléfica verificada.

Em contraposição, há a eugenia chamada de positiva. Nesse caso, não há qualquer doença ou má-formação a ser "corrigida" pela via da biotecnologia, o que existiria seria a possibilidade dos pais determinarem, previamente, certas características que desejassem ver desenvolvidas em seus filhos. Entre os exemplos mais simples estariam a escolha do sexo, da cor dos olhos ou da pele, e, de forma mais complexa, o desenvolvimento de inteligência ou habilidades específicas. Ou seja, aqui há um acréscimo de tecnologia na geração natural do Ser Humano.

Em análise das classificações, entendemos ser fácil a percepção de que a eugenia negativa é mais facilmente aceitável que a positiva. Dificilmente se argumentaria que, mesmo tendo a pré-concepção de que alguém sofreria por toda sua vida com grave doença congênita, e, havendo possibilidade de cura ou atenuação de tal doença via manipulação genética, essa tecnologia não deveria ser utilizada para melhorar a qualidade de vida deste indivíduo.

Já em relação à eugenia positiva, desdobram-se inúmeros imbróglios que nos fazem refletir quase imediatamente sobre sua utilização. Usando o termo habermasiano, a eugenia positiva afetaria a "autocompreensão normativa da espécie" (HABEMAS, 2004) que seria o fato de que o indivíduo geneticamente "modificado" para acréscimo de qualidades ou habilidades deixaria de ser o condutor de seu projeto de vida, sendo um ator a desempenhar um papel traçado previamente por seus pais. A transferência do sonho do pai, projetado no filho, deixaria de ser um esforço educacional e passaria a ser pré-determinado geneticamente.

A autocompreensão normativa da espécie também diz respeito ao entendimento relativo à possibilidade ou não de disposição utilitarista e instrumentalizada da vida humana (mesmo que potencial) para propósitos de seleção.

Nesse tópico, voltamos à eugenia negativa, pois, mesmo considerando-se todos os seus benefícios, não temos uma resposta única sobre a sua utilização irrestrita. Caberia aqui, a discussão se, caso houvesse um diagnóstico genético pré-implantação - DGPI -, com a constatação de doença grave inevitável, abrir-seia a possibilidade dos pais simplesmente optarem pela não implantação e descarte do embrião fecundado?

A pergunta faz eco ao filósofo: "podemos dispor livremente da natureza humana para fins de seleção? [...] a natureza humana é um "bem disponível"? (HABERMAS, 2004, p. 29.). Ou seja, um exame genético seria capaz de determinar a se aquele amontoado de células tem aptidão e dignidade para se "Ser Humano"?

Vislumbramos assim, que mesmo as questões que parecem mais simples dentro da bioética, quando observadas mais detidamente são capazes de suscitar os questionamentos mais complexos.

No caso da eugenia positiva, os questionamentos se multiplicam ainda mais. Nela não há na balança que mede seus benefícios, o peso de uma doença de um lado e todos os riscos envolvidos do outro. Há apenas o desejo egocêntrico de pais que visam determinar o indeterminável (sexo, cor dos olhos), imputar ao seu filho vantagens sobre os demais membros da sociedade (habilidades, inteligência). Nesse sentido, os argumentos contrários hão de ser ainda mais incisivos, uma vez que ainda existe a possibilidade de o indivíduo modificado não concordar com as alterações determinadas por seus pais. 
Além da eugenia positiva e negativa, Habermas (2004) ainda destrinça a eugenia entre liberal e conservadora. Para ele, a eugenia conservadora seria aquela exercida limitadamente, de forma regulamentada e, sobretudo, com a finalidade terapêutica - eugenia negativa. A eugenia conservadora seria orientada, sobretudo pelo Estado, que através da regulamentação disporia os limites a serem observados no exercício dessa ciência.

Já a eugenia liberal, atenderia aos princípios mercadológicos de oferta e demanda, com abertura para o exercício da eugenia positiva no caso de haver procura pelos consumidores dessa tecnologia, nesse sentido, não haveria regulamentação e limitação de qualquer exercício da eugenia por órgãos controladores, ou mesmo pelo Estado, ficando a mercê dos cientistas e dos clientes potenciais a decisão sobre qual a forma de manipulação genética deve ser realizada no embrião.

Caberia, então, o questionamento formulado por Habermas (2004, p. 70) no sentido de que a autopercepção daquele que está sendo alterado geneticamente não seria levada em consideração, quando se trata da eugenia positiva. Claramente, se pudesse se expressar, o indivíduo optaria por não sofrer grave doença, o que justificaria a eugenia negativa - de correção; no entanto, em relação à eugenia positiva, a "visão do interventor" como expõe o filósofo, pode vir a colidir com a daquele que sofre a intervenção, e isso nos traria um dilema que jamais poderá ser respondido na medida em que, o "modificado" geneticamente, após a intervenção, perde até mesmo sua capacidade de opinar, pois não terá conhecido outra realidade.

Nesse ponto, importante trazermos à baila a contraposição deste entendimento realizada por Dworkin (2000). O referido pensador coloca em choque a liberdade de reprodução dos pais e a necessidade de proteção a vida do embrião; para tanto, traça uma possível correspondência entre a eugenia positiva e a educação dos pais.

Explicamos: para ele, sendo o embrião um ser não dotado de sistema nervoso central desenvolvido, não haveria indício de prejuízo ou conflito de interesses entre os pais e o embrião a ser modificado geneticamente, o que inclinaria a discussão para a possibilidade de utilização da eugenia de forma liberal.

Para tanto Dworkin (2000) ainda traça um paralelo entre a educação ministrada pelos pais e a imputação de habilidades pela via genética. Ou seja, se via educação os pais planejarem que o filho devesse ser um pianista, e, para tanto, imputam-lhe aulas exaustivas e pesada carga de exercícios, dificilmente se veriam defensores de que o Estado devesse regular esse tipo de situação. Assim sendo, o pensador defende não haver grande diferença, no caso de os pais, via intervenção genética, imputarem ao filho a habilidade musical em comento, e, portanto, da mesma forma que ocorre em relação ao tipo de educação, o Estado deveria continuar se abstendo de interferir na decisão pessoal dos pais em relação à eugenia positiva.

Contrapondo o posicionamento acima, Habermas (2004) entende que o desenvolvimento de habilidades em decorrência da educação é mais suscetível de autocompreensão e revisão crítica, bem como a possibilidade de decisão pessoal em relação a não compleição do programado por seus pais, mesmo após toda educação ministrada. Já em relação à modificação genética, diminuir-se-ia muito a possibilidade de autodeterminação diversa daquele que foi geneticamente modificado frente à decisão prévia de seus pais.

Tal tema nos deixa a impressão de que, além da própria modificação de imputação de habilidades, poderíamos nos deparar com a possibilidade de modificação do próprio desejo de seguir por determinado caminho, de modo que o embrião, antes mesmo de sua implantação no útero já teria seu destino totalmente traçado por seus pais.

A discussão só se amplia, ao passo que poderíamos estar fronte a possibilidade de reproduções em série de indivíduos que seriam concebidos e gerados com propósito exclusivo de atender a certos anseios sociais. Exemplificativamente, podemos pensar na possibilidade de um país em guerra passar a gerar uma linhagem de homens, com habilidades de combate e já predeterminados a se alistarem nas forças armadas.

Seriam esses Seres Humanos? Haveria dignidade humana nessa vida geneticamente modificada?

Para Fukuyama (2003, p. 19), as pessoas "já não lutam, aspiram, amam, sentem dor, fazem escolhas difíceis, nem fazem qualquer das coisas que associamos tradicionalmente ao ser humano" e, complementando tal entendimento Brownsword (2004) afirma que a emoção seria o elo capaz de conectar 
um indivíduo aos outros, vivos ou mortos, traçando um círculo em que dor, sofrimento, paixão levam a simpatia, coragem, solidariedade, num movimento circular constante. Ou seja, caso a biotecnologia retire a possibilidade das emoções ruins, necessariamente os indíviduos perderiam a capacidade de compaixão.

A defesa da eugenia liberal, com anseios de atender a eugenia positiva nos leva a reflexão sobre o exercício da eugenia natural que sempre foi praticada pelos seres humanos. Na agricultura, se seleciona o melhor grão para replantio, gerando cada vez plantações mais produtivas e duradouras. Da mesma forma na agropecuária, quando se seleciona o melhor gado para reprodução, gerando uma linhagem cada vez mais robusta e produtiva, está-se realizando, de certa forma, a eugenia natural - ou seja, melhoria na linhagem em decorrência de biotecnologia. No entanto, o hiato prevalece quando tratamos dos Seres Humanos.

A complexidade da espécie, bem como a infinitude habilidades por nós desenvolvidas, impede a possibilidade de se selecionar os "melhores" exemplares da espécie e fazer o cruzamento de seus genes, buscando a eugenia natural tal qual se realiza com as plantas e animais, desde os nossos primórdios.

A própria construção social que vivemos impede a realização de tal experiência: não se escolhe parceiros - pelo menos diretamente - por sua compleição genética e sua capacidade de reprodução de bons descendentes.

Assim sendo, a eugenia positiva traz atrativos difíceis de negar, já que o instinto natural presente nos animais em geral - e como tais, também nós, Seres Humanos - deseja que nossos descendentes sejam sempre melhores, e que nossa linhagem ascenda dentro da sociedade. Por isso a discussão em voga é tão relevante, uma vez que sem a regulamentação da matéria, os desejos individuais podem sobrepor-se a própria sociedade, formando indivíduos predeterminados a conquista social, e, muitas vezes, sem os filtros morais necessários ao convívio pacífico e manutenção da própria sociedade.

Da mesma forma, sem a regulamentação, a linha tênue entre o que seria eugenia positiva, e o que seria eugenia negativa, continuaria a cargo do indivíduo - seja o consumidor ou o cientista - o que, novamente, traz possibilidade de desvirtuamento da eugenia negativa com fins ao atingimento de formas de eugenia positiva.

\subsection{Diferentes Concepções de Dignidade humana}

Brownsword (2004) apoiando-se em Fukuyama (2003), nos elenca dois tipos de concepção de dignidade humana que deveriam ser levadas em consideração quando se discute novas tecnologias: dignidade humana como autonomia e dignidade humana como restrição.

A dignidade humana como autonomia poderia ser compreendida com base em três pressupostos: a capacidade individual de fazer as próprias escolhas deve ser reconhecida; as escolhas feitas livremente devem ser respeitadas; e, deve haver um contexto de apoio para que a tomada das decisões (e sua respectiva ação) seja autônoma e livre. ${ }^{3}$ Neste sentido, o autor cita como exemplos de documentos que trariam essa perspectiva a Declaração Universal dos Direitos Humanos de 1948, as Convenções sobre Direitos Econômicos, Sociais e Culturais, e sobre Direitos Civis e Políticos, ambas de 1966. E cita o artigo $1^{\circ}$ da Declaração Universal supracitada que proclama que "todos os seres humanos nascem livres e iguais em dignidade e direitos" (BROWNSWORD, 2004, p. 211, tradução nossa).

Os slogans como "pró-escolha" e "morte com dignidade" exemplificariam essa concepção da Dignidade humana, em que o indivíduo possui plena capacidade de autodeterminação do seu caminho de vida, e, em última instância, até mesmo do momento e forma que deseja morrer (BROWNSWORD, 2004, p. 211)

No entanto, esse exercício da Dignidade humana como autonomia suscita alguns questionamentos, quando analisado sob o enfoque da Biotecnologia. Primeiramente, o autor citado faz um paralelo entre a 3 "[...] Indeed, human dignity as empowerment has its own version of the triple bottom line, namely: that one's capacity for making one's own choices should be recognised; that the choices one freely makes should be respected; and that the need for a supportive context for autonomous decision-making (and action) should be appreciated and acted upon. [...] All human beings are born free and equal in dignity and rights."(BROWNSWORD, 2004, p. 211). 
tecnologia da informação e a biotecnologia; enquanto aquela pode inibir o exercício da autonomia, esta pode alterar o próprio contexto de autonomia. A tecnologia da informação poderia interferir, sobretudo, na privacidade dos indivíduos, o que precisa ser tutelado e protegido. No entanto, a biotecnologia poderia alterar até mesmo o conceito de privacidade, de autotutela, de autodeterminação, uma vez que, dependendo da alteração genética realizada, o indivíduo sequer tem consciência que não está agindo autonomicamente e sim, cumprindo determinações a ele impostas por terceiros, antes mesmo de sua implantação no útero.

De forma exemplificativa a tal afirmação Fukuyama utiliza a ilustração trazida por "Admirável mundo novo", e nos explica:

Em contraste com o homem reduzido pela doença ou a escravidão, as pessoas desumanizadas à maneira de 'Admirável mundo novo' não são infelizes, não sabem que foram desumanizadas e, o que é pior, não se importariam se soubessem. Elas são, na verdade, escravos felizes com uma felicidade abjeta. (FUKUYAMA, 2003, p.19).

As capacidades de alteração da genética humana pela biotecnologia poderiam criar supostas autonomias, ou seja, pessoas que julgam estar fazendo escolhas livres, mas que, na verdade, foram programadas para tanto desde a concepção.

Além disso, ao tratar da biotecnologia, os autores citados - Brownsword (2004) apoiando-se em Fukuyama (2003) - incluem na dignidade humana como autonomia a própria possibilidade de escolha de agir em conformidade com os ditames sociais ou não, ou seja, seria contrário à dignidade humana retirar do indivíduo o poder se de autodeterminar de acordo com as leis e punições estabelecidas pela sociedade. Ou seja, para essa concepção, a utilização de alteração genética para tornar a sociedade livre de crimes afronta a dignidade humana, pois a possibilidade de escolha sobre o cometimento ou não do delito compõe o rol de direitos humanos individuais.

Contrariamente à perspectiva da autonomia, Brownsword (2004, p. 215) traz a concepção de dignidade humana como restrição. Nesse perspectiva, a dignidade humana estabeleceria os limites de atuação do indivíduo. Nesse aspecto, ressalta que os defensores dessa corrente se preocupariam mais com o que deve ser proibido e não da forma com que essa proibição deve ser efetivada.

Cita como exemplos de textos que contém essa perspectiva o Preâmbulo da Convenção dos Direitos Humanos e biomedicina do Conselho da Europa, o Preâmbulo da Declaração Universal da UNESCO (Organização das Nações Unidas para a Educação, a Ciência e a Cultura) sobre Genoma Humano e a Diretiva no 44 do Parlamento Europeu e do Conselho de o6 de julho de 1998, que trata das invenções biotecnológicas.

Ao analisar as duas concepções, Brownsword (2004, p. 218) fazendo uma análise de Fukuyama (2003) conclui que há necessidade de conjugação das duas concepções, quando se trata de analisar e regulamentar a biotecnologia. Essa união visaria preservar a autonomia individual, tanto de participação na revolução biotecnológica, quanto daqueles que preferem não participar, reservando espaço para cada grupo.

Fazendo um paralelo com a teoria de Habermas (2004), poderíamos tender pela primazia da aplicação da concepção da dignidade humana como autonomia quando nos referíssemos à eugenia negativa, uma vez que se permitiria a opção dos pais sobre a correção ou não de características e doenças genéticas percebidas no embrião.

Contrariamente, teríamos a aplicação da concepção de dignidade humana como restrição nos casos da eugenia positiva, quando deveria haver uma regulação sobre quais os aspectos serão permitidos e quais serão proibidos de comporem o rol de possibilidade de determinação pelos pais.

\subsection{A Regulamentação da Biotecnologia}

Após análise das diferentes concepções de eugenia propostas por Habermas, bem como as diferentes concepções de dignidade humana proposta por Fukuyama, devemos analisar, primeiramente, 
se a Biotecnologia deve, de fato, ser regulamentada por órgãos de controle, e, sendo positiva a resposta a este questionamento, passaremos a analisar um pouco dos desafios a serem enfrentados pelos entes que tiverem a incumbência de normatizar o tema.

Conforme salientamos anteriormente, Habermas (2004) éamplamente favorável à regulamentação da Biotecnologia. Segundo o referido filósofo, é necessária discussão sobre o direito de "uma herança genética não manipulada", mas sem excluir a possibilidade da eugenia negativa, que, atenderia - num primeiro momento - aos requisitos da dignidade humana e dos direitos humanos, uma vez que, se pudesse ser consultado, provavelmente, o feto optaria por não sofrer a doença que lhe era predisposta geneticamente. Logo, não haveria possível choque entre a decisão dos pais e do filho, fato este que não poderia ser pressuposto no caso da eugenia positiva.

No mesmo sentido, o filósofo ainda traz à baila o debate acerca do questionamento se feto ainda não implantado no útero seria um "bem material", e se, por isso, não receberia status de sujeito de direitos, ou se ao feto pré-implantação seriam concedidos direitos e garantias, inclusive sobrepondo-se estes direitos à possível decisão dos seus pais (HABERMAS, 2004, p. 44).

Somando-se a tal indagação, temos Fukuyama (2003), defendendo a necessidade de regulamentação da biotecnologia por parte do Estado, afirmando que o controle não deve ficar a cargo apenas dos cientistas e dos indivíduos "consumidores" desse mercado tecnológico, muito menos, a cargo das empresas e indústrias que lucram com referidas pesquisas e experimentos, nem de políticos que influenciados por possíveis benefícios pessoais, ou de lucro via impostos e geração de empregos por parte das empresas acima citadas, poderiam ser tendenciosos no sentido da permissividade da eugenia liberal. Assim sendo, o autor complementa:

Aristóteles sustentou, de fato, que as noções humanas de certo e errado - o que hoje chamamos de direitos humanos - fundavam-se em última análise na natureza humana. Isto é, sem compreender como desejos, propósitos, traços e comportamentos naturais se conjugam num todo humano, não podemos compreender metas humanas ou fazer julgamentos sobre certo e errado, bom e mau, justo e injusto. Como muitos filósofos utilitaristas mais recentes, Aristóteles acreditava que o bem era definido pelo que as pessoas desejavam; mas enquanto os utilitaristas procuram reduzir os fins humanos a um simples denominador comum, como o alívio do sofrimento ou a maximização do prazer, Aristóteles conservou uma visão complexa e nuançada da diversidade e grandeza dos fins humanos. O objetivo de sua filosofia foi tentar distinguir o natural do convencional e ordenar racionalmente os bens humanos. (FUKUYAMA, 2003, p. 26).

Os autores utilitaristas modernos preferem interpretar a felicidade não como uma soma de prazeres, mas como a satisfação ou não frustração dos desejos ou interesses que qualquer pessoa possa ter. Dessa forma, se conjugarmos a visão utilitarista individualista atual, e a eugenia liberal, colocarse-ia o futuro da espécie humana nas mãos de cada indivíduo, que poderia decidir autonomamente as modificações genéticas de sua prole.

Ainda no tema da necessidade de regulamentação da biotecnologia, temos o fato de que o acesso a tal ciência, como qualquer inovação tecnológica, é de alto custo, e, dessa forma, acentuar-se-ia a discrepância social entre os indivíduos que tiveram acesso à eugenia positiva - já advindos de classes mais abastadas, e que teriam acesso à tecnologia pioneira - e aqueles que não tiveram acesso à eugenia positiva (seja por escolha ou por ausência de recursos).

Lembrando aqui que a eugenia positiva visa imputar habilidades aos embriões, acrescentando à balança da desigualdade social o item em que, os geneticamente modificados já nasceriam predispostos a serem excelentes em algum setor de sua vida, partindo em larga vantagem aos que não tiveram a oportunidade de ter esse upgrade genético. Como ilustração do aqui explicitado, temos o filme "Gattaca - Experiência Genética" em que um pianista, já pré-concebido para tal finalidade, é geneticamente modificado para ter vinte dedos nas mãos, e assim, ter uma vantagem genética imensa sobre pianistas com "somente" dez dedos. 
No referido filme, inclusive, se demonstra que certos locais e setores da sociedade eram exclusivos para indivíduos frutos da modificação genética, sendo que a entrevista de emprego para alguns cargos consistia na coleta do sangue do candidato e aferição de sua compleição genética.

Pode parecer absurdo, e que tal imagem é fruto de uma ficção que jamais será realidade, no entanto, devemos ressaltar que comunicações via imagem em tempo real entre as pessoas em locais diversos do mundo, hologramas, sistemas de localização via satélite também já foram tema de ficção científica e considerados irrealizáveis. Portanto, não podemos, sob nenhum aspecto, minimizar o potencial de influência da eugenia positiva na sociedade.

Deixar a eugenia positiva a cargo da vontade individual traria a situação em que

se pais abastados se virem subitamente diante da oportunidade de aumentar a inteligência de seus filhos, assim como a de todos os seus descendestes, teremos os ingredientes não apenas de um dilema moral, mas de uma guerra de classes total (FUKUYAMA, 2003, p. 29).

E acrescentamos, não só o acréscimo de inteligência, como qualquer tipo de habilidade individual, traria um desequilíbrio de classes ainda maior entre aqueles que tiverem acesso à modificação genética e os que não tiverem tal tecnologia ao alcance.

Sob esse aspecto, e com fundamento em toda argumentação de Habermas (2004), inclusive a refutação deste aos argumentos de Dworkin (2000), e ainda, trazendo o alicerce de Fukuyama (2003) estamos inclinados a concordar com os posicionamentos que elencam a necessidade de regulação da biotecnologia, pois as consequências da eugenia positiva à dignidade humana são grandes e justificam o cerceamento da liberalidade total de pesquisa e da possibilidade de escolha individual dos pais em defesa da dignidade humana da coletividade.

\subsubsection{Os desafios regulatórios}

Após atingirmos o entendimento de que a regulação da biotecnologia é realmente necessária, faremos um estudo sobre os desafios potenciais que essa regulamentação enfrentaria para sua efetivação, nos levando a outras reflexões importantes sobre o tema. Para tanto, tomaremos fundamento em Brownsword (2004).

Em primeiro lugar, ressalta-se a imensa dificuldade de uma regulação global sobre o tema. Cada localidade parte de uma concepção individual, tanto econômica, quanto cultural. Há locais que seriam naturalmente mais predispostos ao incentivo à ciência (aqueles que têm uma perspectiva mais positiva, acreditando na ciência como alavancadora de benefícios e avanços), já outras localidades seriam mais resistentes à ciência, pois têm uma visão mais voltada ao risco de seu exercício (perspectiva negativa). (BROWNSWORD, 2004).

Ademais, temos as mais diversas concepções filosóficas e religiosas de cada localidade (podendo variar de acordo com cada governo no poder, principalmente nos países em que religião e Estado se confundem), somadas aos interesses econômicos envolvidos, que levariam as localidades em que se desenvolvem técnicas de eugenia positiva a serem naturalmente tendenciosas pela não regulamentação, por temor de afastar os investimentos da área, levando à temida eugenia liberal.

Aliando todos esses desafios elencados, o primeiro desafio proposto já se demonstraria quase intransponível.

Nesse ponto, a variação inevitável de regulamentações locais sobre a biotecnologia dificultaria enormemente a possibilidade de compliance global, levando a existência de regimes mais abertos à biotecnologia e outros mais fechados. Correndo-se o risco, então, da criação de verdadeiras ilhas de regulamentação, paraísos em quea normatização deixa a eugenia ser exercida de forma liberal, prejudicando todos os demais locais em que a regulamentação foi elaborada para coibir a utilização da eugenia positiva, 
em proteção a dignidade humana.

Dizemos isso, pois os indivíduos que forem "produzidos" nesses locais isentos de regulamentação, serão geneticamente modificados positivamente, mas, por óbvio, não ficarão restritos a viver nesse mesmo local - senão estaríamos criando uma prisão sem crime - e, assim sendo, podem se deslocar livremente entre locais regulamentados ou não, gerando discrepância entre indivíduos não modificados e indivíduos modificados geneticamente.

Além disso, a rapidez com que as novas tecnologias surgem, bem como o fato de que muitas pesquisas correm em sigilo, para proteção de segredos industriais e patentes, colabora para a dificuldade de regulamentação, já que a normatização estaria sempre um passo atrás das tecnologias disponíveis, e os cientistas que têm a intenção de desenvolver a eugenia positiva, poderiam burlar as regras existentes buscando novas formas de realização técnica não açambarcada na norma vigente.

Neste sentido, seria importante que a regulamentação não visasse ser exaustiva em termos técnicos - que estão em constante alteração -, o que faria com que a norma ficasse rapidamente obsoleta, abrindo espaço às lacunas. A regulação deveria ter cunho moral e ético, proibindo ou permitindo os resultados almejados com a biotecnologia, independentemente da técnica utilizada.

Por fim, dentre tantos desafios, um dos que entendemos ser dos mais desafiadores é a definição de quem deveria ser o responsável pela regulação da biotecnologia. Isso porque, como o próprio Habermas (2004) explicita, são tantos interesses envolvidos, que dificilmente se encontrará uma entidade efetivamente neutra, alheia às influencias dos interesses contrários ou favoráveis à eugenia liberal.

De um lado, temos a força imensa das indústrias e empresas de fármacos, bem como pesquisadores, e, em última instância, os próprios consumidores que desejam realizar alterações genéticas positivas em seus filhos. Do outro lado, temos os defensores da eugenia conservadora, limitada, restrita apenas a algumas formas de eugenia negativa, corretiva, sem a abertura para a eugenia positiva.

Neste diapasão, teríamos a dificuldade de encontrar um órgão que, ao mesmo tempo em que tivesse amplitude global - como dito anteriormente - fosse forte o suficiente para ser respeitado pelos favoráveis à eugenia liberal, ou seja, não poderia ser um ente que, mesmo existente, pudesse ser ignorado pelos cientistas e indústrias, que levariam a cabo seus estudos e efetivariam as alterações gênicas, mesmo proibidas.

Da mesma forma, seria necessária a criação de um ente que pudesse resistir às investidas financeiras e de influência que o lado que defende a eugenia liberal tem a capacidade de realizar. Nesse sentido, contrariamente a Fukuyama (2003) temos resistência à idéia de que o controle deva ser passado ao Estado, já que o exercício de lobby e influência financeira não passa alheio a maioria dos governos do mundo, o que desestabilizaria a balança para permissividade das técnicas da eugenia positiva.

Portanto, pensamos que deveria ser criado um órgão supranacional, com capacidade de influência global, possivelmente ligado a alguma entidade que tivesse força coercitiva, para punir quem descumprisse a normatização estatuída, e que tivesse sua composição formada por membros das mais diversas áreas do conhecimento, tanto das ciências exatas e biológicas, que tratariam das questões técnicas, como das áreas da filosofia, ciências sociais e sociais aplicadas, que poderiam analisar os parâmetros de benefícios e malefícios em perspectiva, a cada nova tecnologia desenvolvida.

Todas essas dificuldades elencadas, só ressaltam o fato de que o posicionamento neutro, ou indiferente sobre o tema da regulação da biotecnologia, traz consigo a tendência à ampliação da eugenia liberal, já que ela é a regra, e, enquanto não houver um movimento global de regularização - de forma a uniformizar os entendimentos das permissividades e proibições - fatalmente haverá locais que, visando o lucro propiciado pelas indústrias e empresas interessadas, permanecerão como paraísos isentos de controle, prejudicando todo o restante dos indivíduos, já que, conforme vimos, a eugenia liberal tem potencial de prejudicar, não só o indivíduo modificado, mas todo o entendimento do que é a própria raça humana. 


\section{CONSIDERAÇÕES FINAIS}

Por tudo exposto, buscamos estudar o desafio do desenvolvimento da biotecnologia sob a perspectiva do respeito à Dignidade humana. Para isso, focamos no estudo da biotecnologia com olhar sobre a eugenia, analisando o referido tema com enfoque no estudo de Jürgen Habermas, e, tendo por base sua classificação. Nesse sentido, desenvolvemos entendimento no sentido de que a eugenia negativa, ou seja, de correção de possíveis doenças do embrião deve ser desenvolvida e fomentada, já que vai ao encontro da perspectiva da dignidade humana, sem alteração da capacidade de autodeterminação individual.

Em contrapartida, em relação à eugenia positiva - aquela que vislumbra acréscimo de habilidades ou características físicas ao embrião - essa deve ser proibida, uma vez que é insidiosa para com a capacidade de autotutela do indivíduo, que teria uma vida traçada por terceiros, perdendo a capacidade de determinar seu caminho, e, de forma ainda mais assustadora, sem que este sequer saiba que não está seguindo passos por ele traçados, mas sim por outrem.

Nesse sentido, havendo necessidade de regulação do tema, caminhamos para a adoção da eugenia conservadora, que tem parâmetros éticos, técnicos e morais como limitadores de seu exercício pelos cientistas; este posicionamento é contrário ao entendimento de Ronald Dworkin, que considera não haver prejuízo na eugenia liberal, ficando a cargo dos desenvolvedores da tecnologia e dos consumidores da mesma a opção da amplitude da interferência genética embrionária a ser realizada.

Ato contínuo, traçamos um paralelo entre as diferentes concepções de dignidade humana para Fukuyama - como autonomia e como restrição -, e, as as percepções de diferentes eugenias trazidas por Habermas (positiva e negativa), entendemos que ambas as teorias de dignidade humana são relevantes quando se trata de regulamentação da biotecnologia. A percepção de dignidade humana como autonomia aplicar-se-ia ao contexto da eugenia negativa, quando ficaria a cargo da família a decisão sobre a intervenção genética corretiva ou não.

De modo diverso, quando tratamos da eugenia positiva, dever-se-ia adotar a concepção de dignidade humana como restrição, ou seja, seria necessária a imposição de limites para exercício de tal tecnologia, tirando das mãos dos profissionais da biotecnologia e dos consumidores interessados a decisão de intervenção.

Assim sendo, concluímos pela necessidade de regulamentação, e, diante desse desafio, buscamos traçar um esboço dos principais desafios que seriam encontrados pelo órgão normatizador do tema, dentre os quais demos destaque à agilidade com que se desenvolvem novas tecnologias, e, portanto o instrumento regulador deveria ser construído de forma a permanecer o maior tempo possível vigente, sem delimitar técnicas específicas proibidas ou permitidas, devendo focar nos bens jurídicos tutelados e impedindo que os mesmos sejam vilipendiados, independentemente da técnica utilizada.

Além disso, uma grande dificuldade a ser minimizada seria a diversidade das regulamentações locais e regionais, o que prejudicaria sobremaneira a comunidade global como um todo, tendo em vista o fato de que os indivíduos geneticamente modificados jamais ficarão restritos ao local em que houve a efetivação da alteração, o que influenciaria a comunidade mundial como um todo, à medida que houvesse o trânsito desses indivíduos; portanto, é importante que sejam traçadas diretrizes gerais globais, evitando a guerra comercial de interesses por zonas livres de regulamentação.

O presente estudo, longe de buscar esgotar as respostas sobre o tema, visa trazerà tona a necessidade de envolvimento de toda comunidade científica - de reguladores da área jurídica, aos desenvolvedores da área biológica - e explicitar que, a posição neutra somente favorece a eugenia liberal (tendenciosa à eugenia positiva). Dessa forma, importante que haja estudo do ponto de vista ético e moral sobre os possíveis efeitos da eugenia na sociedade, para que possamos nos posicionar de forma firme sobre o tema; independentemente do "lado" que se tome nesse embate, o que não pode prevalecer é a passividade sobre tema tão importante. 


\section{REFERÊNCIAS}

BROWNSWORD, Roger. What the world needs now: Techno-regulation, human rights and human dignity. Global governance and the quest for justice. Oxford, p. 203-234, 2004.

CRUZ, Álvaro Ricardo de Souza. O discurso Científico na Modernidade: O conceito de paradigma é aplicável ao direito? Rio de Janeiro: Lumen Juris, 2009.

DWORKIN, R.Sovereign Virtue. The Theory and Practice of Equality. Cambridge: Harvard University Press, 2000.

DUTRA, Delamar José Volpato. Razão e consenso em Habermas - a teoria discursiva da verdade, da moral, do direito e da biotecnologia. Florianópolis: Editora da UFSC, 2005.

FOUCAULT, Michel. Nascimento da Biopolítica - curso dado no Collège de France (1978-1979). São Paulo: Martins Fontes, 2008.

FUKUYAMA, Francis. Nosso Futuro Pós-Humano - Consequências da revolução da biotecnologia. Tradução de Maria Luiza X. de A. Borges. Rio de Janeiro: Rocco, 2003.

GATTACA - uma experiência genética. Direção: Andrew Niccol. Intérpretes: Ethan Hawke; Uma Thurman; Jude Law; Loren Dean. EUA, Sony Pictures, 1997. Disponível em: <https://pt.wikipedia.org/ wiki/Gattaca>. Acesso em: 28 jul. 2017.

GOLDIM, José Roberto (1998). Eugenia. UFRGS. Disponível em: < https://www.ufrgs.br/bioetica/ eugenia.htm >. Acesso em: 22 jul. 2017.

HABERMAS, Jürgen. O futuro da natureza humana: a caminho de uma eugenia liberal? São Paulo: Martins Fontes, 2004.

HUXLEY, Aldous. Admirável Mundo Novo. 2. ed. São Paulo: Globo, 2001.

KOOPS, Bert-Jaap. Criteria for Normative Technology: An Essay on the Acceptability of Code as Law'in Light of Democratic and Constitutional Values. Oxford, Hart Publishing, p. 157-174, 2007.

KUHN, Thomas S. A estrutura das revoluções científicas. 10. ed. São Paulo, SP: Perspectiva, 2011.

MOSER, Antônio. Biotecnologia e bioética: para onde vamos? Petrópolis: Vozes, 2004.

ORWELL, George. 1984. Nova York: Knopf, 1999.

ROCHA, Carmem Lúcia Antunes. Direito à Vida Digna. Belo Horizonte: Ed. Forum, 2004.

THOMASMA, David C. Evolving Bioethics and International Human Rights. Autonomy and Human Rights in Health Care, p. 11-24, 2008.

ZUBEN, Newton Aquiles von. Bioética e Tecnociências: a saga de Prometeu e a esperança paradoxal. Bauru, SP: Edusc, 2006. 